\title{
Sistem Pakar Diagnosis Potensi Penyebaran Penyakit pada Tanaman Cabai Menggunakan Fuzzy Mamdani
}

\author{
Deni Setiyo Wibowo ${ }^{1)}$, Yessy Yanitasari*,1), Dedih ${ }^{2)}$ \\ 1) Teknik Informatika, STMIK Kharisma Karawang, Indonesia \\ Jl. Pangkal Perjuangan Km.1 Bypass, Karawang, Indonesia 41316 \\ 2) Sistem Informasi, STMIK Kharisma Karawang, Indonesia \\ Jl. Pangkal Perjuangan Km.1 Bypass, Karawang, Indonesia 41316
}

Cara sitasi: D. S. Wibowo, Y. Yanitasari, and D. Dedih, "Sistem Pakar Diagnosis Penyakit pada Tanaman Cabai Menggunakan Fuzzy Mamdani," Jurnal Teknologi dan Sistem Komputer, vol. 6, no. 2, Apr. 2018. doi: 10.14710/jtsiskom.6.2.2018.71-75, [Online].

\begin{abstract}
This research developed expert system using fuzzy Mamdani to diagnose the spread of diseases affecting the growth of chili plants based on environmental factors. Environmental variables used as fuzzy input parameters are soil pH, air temperature, air humidity and solar irradiation. The input-output relationship uses 81 rules with the AND operator and the MIN implication function. For a case, the results showed that the percentage of the potential spread of the disease showed $60.25 \%$, so the category of potential disease spread with soil $\mathrm{PH} 7.5 \mathrm{pH}, 28{ }^{\circ} \mathrm{C}$ air temperature and air humidity $75 \mathrm{RH}$ and $35 \%$ sun irradiance is moderate.
\end{abstract}

Keywords - chilli desease; expert system; fuzzy Mamdani.

Abstrak - Penelitian ini mengembangkan sistem pakar menggunakan fuzzy Mamdani untuk mendiagnosis penyebaran penyakit yang mempengaruhi pertumbuhan tanaman cabai berdasarkan faktor lingkungan. Variabel lingkungan yang digunakan sebagai parameter masukan fuzzy yaitu pH tanah, suhu udara, kelembaban udara dan penyinaran matahari. Relasi masukan-keluaran menggunakan 81 aturan dengan operator AND dan fungsi implikasi MIN. Untuk satu kasus, hasil penelitian menunjukkan nilai persentase potensi penyebaran penyakit adalah $60,25 \%$, sehingga kategori potensi penyebaran penyakit dengan $\mathrm{PH}$ tanah $7.5 \mathrm{pH}$, suhu udara $28^{\circ} \mathrm{C}$, kelembaban udara $75 \mathrm{RH}$ dan penyinaran matahari $35 \%$ adalah sedang.

Kata Kunci - penyakit cabai; sistem pakar; fuzzy Mamdani

\section{Pendahuluan}

Dua spesies cabai sebagai komoditas sayuran yang bernilai ekonomi tinggi dan terkenal di indonesia adalah cabai besar dan cabai kecil [1]. Cabai yang termasuk ke dalam cabai besar adalah cabai merah, cabai hijau,

*) Penulis korespondensi (Yessy Yanitasari)

Email: yessy.yanitasari@gmail.com paprika, dan cabai keriting, sedangkan yang termasuk ke dalam golongan cabai kecil adalah cabai rawit, cabai kancing, cabai udel, dan cabai yang biasanya dipelihara sebagai tanaman hias. Luas area lahan cabai menurut data terakhir di pulau jawa sekitar 230.000 hektar dan merupakan suatu usaha budidaya yang terluas dibandingkan komoditas sayuran lainnya. Namun, produksi rata-rata nasional tanaman cabai baru mencapai 5,78 ton/hektar, masih jauh di bawah potensi hasilnya yang berkisar antara 12 sampai 20 ton/hektar [2]. Untuk satu kasus di Garut, faktor penyebab masih rendahnya jumlah produksi tanaman cabai adalah produktivitas lahan yang rendah akibat erosi sebesar $30 \%$, penguasaan teknologi budidaya cabai yang rendah sebesar $10 \%$, belum banyaknya penggunaan bibit varietas dengan hasil tinggi dan berkualitas sebesar $20 \%$ dan serangan organisme pengganggu tanaman sebesar $20 \%$ [3].

Terdapat 20 jenis penyakit yang dapat menyerang tanaman cabai [4]. Namun, proses deteksinya sulit dilakukan karena adanya kemiripan gejala yang ditimbulkan dan membuat para petani tidak dapat menentukan metode pencegahan dan pengendalian yang tepat untuk mengatasi penyakit tersebut. Dalam diagnosis penyakit diperlukan kecermatan dan ketelitian dari pakar atau ahli terhadap gejala yang mengindikasikan suatu penyakit karena adanya kemiripan pada gejala-gejala tersebut. Kesalahan diagnosis dari gejala yang ada menyebabkan perbedaan hasil diagnosis dengan penyakit yang sebenarnya diderita oleh tanaman cabai. Jika salah dalam menerapkan metode pencegahan dan pengendalian untuk menangani suatu penyakit, maka penyakit tidak dapat diatasi secara tepat sehingga tanaman akan tetap terjangkiti penyakit tersebut. Kemungkinan terburuk adalah tanaman akan mengalami kematian dan petani mengalami gagal panen.

Sistem pakar yang berbasis pengetahuan yang terekam dalam komputer dapat diterapkan untuk mendiagnosis penyakit tanaman cabai dengan beragam algoritme [5]-[8]. Nusantara dkk. [5] mengembangkan sistem pakar diagnosis penyakit tanaman cabai merah dengan metode backward chaining, sedangkan Fuljana [6] menggunakan forward chaining. Muslim dkk [7] mengembangkan dengan menggunakan teorema Bayes 
Tabel 1. Analisis faktor lingkungan dan potensi penyebaran penyakit

\begin{tabular}{|c|c|c|}
\hline No & Faktor Lingkungan & Nilai parameter \\
\hline \multirow[t]{4}{*}{1} & $\mathrm{pH}$ tanah & \\
\hline & a. Rendah & $1-5$ \\
\hline & b. Sedang & $4-8$ \\
\hline & c. Tinggi & $7-14$ \\
\hline \multirow[t]{4}{*}{2} & Suhu udara & \\
\hline & a. Rendah & $5-20^{\circ} \mathrm{C}$ \\
\hline & b. Sedang & $15-30{ }^{\circ} \mathrm{C}$ \\
\hline & c. Tinggi & $25-40{ }^{\circ} \mathrm{C}$ \\
\hline \multirow[t]{4}{*}{3} & Kelembaban udara & \\
\hline & a. Rendah & 20-60 RH \\
\hline & b. Sedang & $50-80 \mathrm{RH}$ \\
\hline & c. Tinggi & 70-100 RH \\
\hline \multirow[t]{4}{*}{4} & Penyinaran matahari & \\
\hline & a. Rendah & $20-40 \%$ \\
\hline & b. Sedang & $30-70 \%$ \\
\hline & c. Tinggi & $60-100 \%$ \\
\hline \multirow[t]{4}{*}{5} & Penyebaran penyakit & \\
\hline & a. Rendah & $1-40 \%$ \\
\hline & b. Sedang & $40-80 \%$ \\
\hline & c. Tinggi & $80-100 \%$ \\
\hline
\end{tabular}

dan Mulyanto [8] dengan menggunakan fuzzy Mamdani untuk diagnosis penyakit tanaman cabai.

Sistem pakar tersebut di atas berfokus untuk mendeteksi penyakit cabai merah berdasarkan parameter tumbuhan, di antaranya warna daun, bercak daun dan diameternya dan warna batang. Potensi penyebaran untuk pencegahan dan pengendalian penyakit cabai tersebut belum ada yang membahas. Penelitian ini mengembangkan sistem pakar untuk mendeteksi dini penyebaran penyakit cabai merah berdasarkan empat parameter lingkungan, yaitu $\mathrm{PH}$ tanah, suhu udara, kelembaban udara, dan penyinaran matahari. Algoritma yang digunakan adalah fuzzy Mamdani, seperti dalam Mulyanto [8]. Sistem fuzzy Mamdani ini tidak dapat bekerja dengan kapasitas penuh seperti halnya fuzzy Sugeno, walaupun mempunyai performansi yang mirip dengan fuzzy Sugeno, seperti dalam aplikasi sistem pengkondisi udara [9] dan penjadwalan real-time dengan fuzzy [10]. Namun, dalam perbandingan tingkat ketepatan deteksi, fuzzy Mamdani mempunyai performansi lebih baik daripada fuzzy Sugeno, seperti dinyatakan dalam Ayunningtias dkk. [11] untuk prediksi jumlah pendaftar mahasiswa baru di UIN Gunung Djati Bandung dan Batubara [12] untuk penentuan kualitas cor beton instan.

\section{Metode Penelitian}

Faktor lingkungan yang mempengaruhi pertumbuhan tanaman dan penyebaran penyakit tanaman serta relasinya untuk membentuk variabelvariabel dan aturan-aturan fuzzy diperoleh dari wawancara dengan seorang pakar dari Balai Besar Peramalan Organisme Pengganggu Tumbuhan Karawang. Faktor lingkungan sebagai masukan sistem tersebut adalah $\mathrm{pH}$ tanah, suhu udara, kelembaban udara
Tabel 2. Himpunan fuzzy masukan dan keluaran

\begin{tabular}{lllll}
\hline No & Variabel & Himpunan & $\begin{array}{l}\text { Fungsi } \\
\text { Keanggotaan }\end{array}$ & Parameter \\
\hline 1 & PH Tanah & Rendah & Bahu kiri & {$[1 ; 3 ; 5]$} \\
& $(\mathrm{pH})$ & Sedang & Trapesium & {$[4 ; 5 ; 7 ; 8]$} \\
& & Tinggi & Bahu Kanan & {$[7 ; 10 ; 14]$} \\
2 & Suhu Udara & Rendah & Bahu kiri & {$[5 ; 15 ; 20]$} \\
& $\left({ }^{\circ} \mathrm{C}\right)$ & Sedang & Trapesium & {$[15 ; 20 ; 25 ; 30]$} \\
& & Tinggi & Bahu Kanan & {$[25 ; 35 ; 40]$} \\
3 & Kelembab & Rendah & Bahu kiri & {$[20 ; 40 ; 60]$} \\
& an Udara & Sedang & Trapesium & {$[50 ; 60 ; 70 ; 80]$} \\
& (RH) & Tinggi & Bahu Kanan & {$[70 ; 90 ; 100]$} \\
4 & Penyinaran & Rendah & Bahu kiri & {$[20 ; 30 ; 40]$} \\
& Matahari & Sedang & Trapesium & {$[30 ; 40 ; 60 ; 70]$} \\
& $(\%)$ & Tinggi & Bahu Kanan & {$[60 ; 80 ; 100]$} \\
5 & Potensi & Rendah & Bahu kiri & {$[10 ; 20 ; 40]$} \\
& Penyakit & Sedang & Trapesium & {$[30 ; 40 ; 60 ; 70]$} \\
& & Tinggi & Bahu Kanan & {$[60 ; 80 ; 100]$} \\
\hline
\end{tabular}

Tabel 3. Aturan fuzzy Mamdani untuk potensi penyebaran

\begin{tabular}{cclll}
\hline $\begin{array}{c}\text { Atur pH } \\
\text { an }\end{array}$ & $\begin{array}{l}\text { Suhah } \\
\text { udara }\end{array}$ & $\begin{array}{l}\text { Kelembab } \\
\text { an udara }\end{array}$ & $\begin{array}{l}\text { Sinar } \\
\text { matahari penyebaran }\end{array}$ & $\begin{array}{l}\text { Potensi } \\
\text { mah }\end{array}$ \\
\hline 1 & rendah rendah rendah & rendah & rendah \\
2 & rendah rendah rendah & sendang & rendah \\
3 & rendah rendah rendah & tinggi & rendah \\
4 & rendah rendah sedang & rendah & sedang \\
5 & rendah rendah sedang & sendang & sedang \\
6 & rendah rendah sedang & tinggi & sedang \\
7 & rendah rendah tinggi & rendah & tinggi \\
& & & & \\
79 & rendah rendah tinggi & sendang & tinggi \\
80 & rendah rendah tinggi & tinggi & tinggi \\
81 & rendah sedang rendah & rendah & rendah \\
\hline
\end{tabular}

dan penyinaran matahari. Pernyataan fuzzy untuk keempat faktor lingkungan tersebut dan potensi penyebaran penyakit cabai dinyatakan dalam Tabel 1 . Lama penyinaran matahari diambil sebagai persentase rata-rata lamanya penyinaran matahari harian dari jam 07.00 - 17.00 Waktu Indonesia Barat.

Metode yang digunakan adalah fuzzy Mamdani dengan empat faktor lingkungan sebagai variabel fuzzy masukan dan potensi penyebaran penyakit sebagai variabel fuzzy keluaran. Pernyataan tersebut dibentuk menjadi himpunan fuzzy seperti yang dinyatakan dalam Tabel 2.

Relasi masukan-keluaran dalam sistem fuzzy Mamdani ini menggunakan 81 aturan seperti yang dinyatakan dalam Tabel 3 (aturan secara lengkap dinyatakan dalam lampiran Tabel A.1). Operator yang digunakan untuk menghubungkan antara dua masukan adalah operator AND dan yang memetakan antara masukan-keluaran adalah IF-THEN. Fungsi implikasi yang digunakan adalah MIN, yang berarti tingkat keanggotaan yang didapat sebagai konsekuen dari proses 
ini adalah nilai minimum dari variabel $\mathrm{pH}$ tanah, suhu udara, suhu udara dan penyinaran matahari untuk mendapatkan daerah fuzzy pada variabel nilai penyebaran penyakit untuk masing-masing aturan.

Komposisi aturan menggunakan fungsi MAX, yaitu dengan mengambil tingkat keanggotaan maksimum dari tiap konsekuen aplikasi fungsi implikasi. Fungsi penegasan (defuzzifikasi) untuk menentukan nilai potensi penyakit tanaman cabai menggunakan metode centroid seperti yang dinyatakan dalam Persamaan 1 .

$$
Z=\frac{\int_{a}^{b} z \mu(z) d z}{\int_{a}^{b} \mu(z) d z}
$$

\section{Hasil dan Pembahasan}

Faktor yang mempengaruhi status penyebaran penyakit tanaman cabai (capsicum annum l) berdasarkan faktor lingkungan yang terdiri dari $\mathrm{pH}$ tanah, suhu udara, kelembaban udara dan penyinaran matahari. Berikut dinyatakan himpunan fuzzy dan fungsi keanggotaan dari variabel $\mathrm{pH}$ tanah, suhu udara, kelembaban udara, penyinaran matahari dan potensi penyakit.

Himpunan fuzzy variabel $\mathrm{pH}$ tanah, suhu udara, kelembaban udara, penyinaran matahari dan potensi penyebaran penyakit masing-masing memiliki 3 nilai, yaitu rendah, sedang dan tinggi. Himpunan tersebut dinyatakan dalam kurva Gaussian seperti ditunjukkan pada Gambar 1, Gambar 2, Gambar 3, Gambar 4 dan Gambar 5 .

Dalam melakukan analisis sistem fuzzy ini, digunakan sebuah studi kasus dimana tanaman cabai (capsicum annum l) terdiagnosis penyakit embun tepung. Petani ingin mengetahui kemungkinan potensi penyebaran penyakit pada tanah dengan $\mathrm{pH}$ tanah 7,5 , suhu udara $28^{\circ} \mathrm{C}$ dan kelembaban udara $75 \mathrm{RH}$ dan penyinaran matahari 35\%. Parameter $\mathrm{pH}$ tanah, suhu dan kelembaban udara masing-masing mempunyai derajat keanggotaan sedang dan tinggi. Parameter penyinaran matahari mempunyai derajat keanggotaan rendah dan sedang.

Fungsi implikasi untuk masukan parameter tersebut menggunakan MIN dan relasi masukan-keluaran sistem menggunakan operator AND dan aturan-aturan seperti dinyatakan dalam Tabel 3. Fungsi implikasi tersebut melibatkan 13 aturan seperti ditunjukkan dalam Gambar 6 (implikasi lengkap dinyatakan dalam lampiran Gambar A.1).

Komposisi aturan menggunakan fungsi MAX untuk mengambil kesimpulan secara keseluruhan berdasarkan tingkat keanggotaan maksimum dari tiap konsekuen. Komposisi aturan untuk kasus tersebut ditunjukkan dalam Gambar 7 yang dibagi menjadi 3 bagian, yaitu A1, A2, dan A3. Dari hasil komposisi aturan tersebut, fungsi keanggotaannya dapat dinyatakan dalam Persamaan 2 yang diperoleh dengan mencari nilai $a_{1}$ dan $a_{2}$ dengan perhitungan sebagai sebagai berikut:

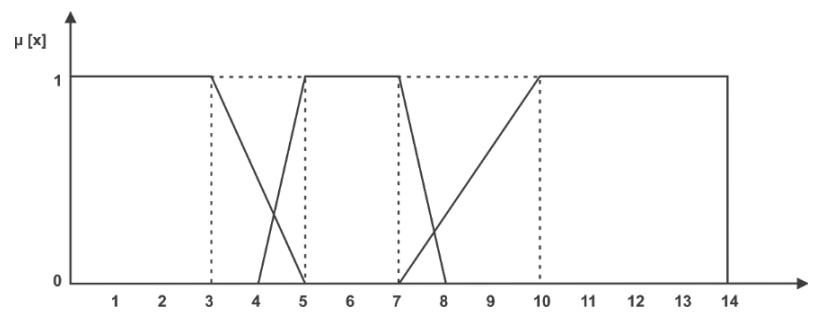

Gambar 1. Himpunan fuzzy $\mathrm{pH}$ tanah

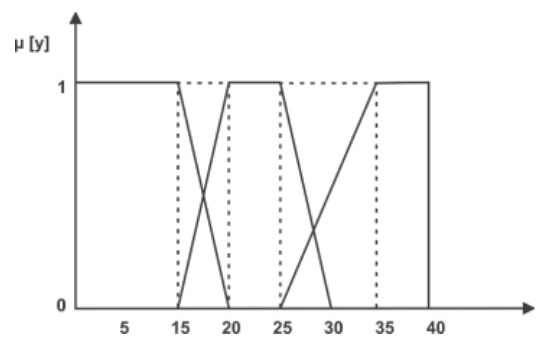

Gambar 2. Himpunan fuzzy suhu udara

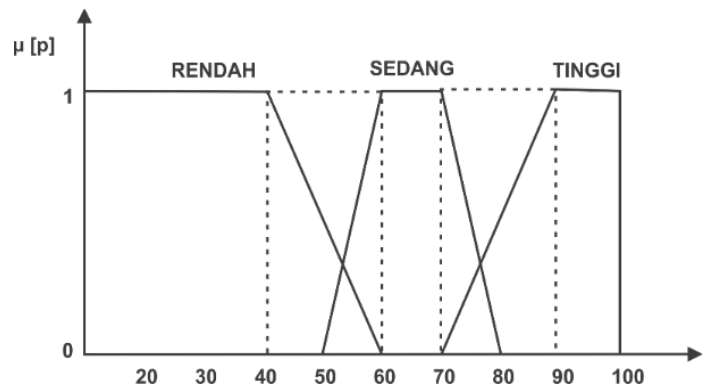

Gambar 3. Himpunan fuzzy kelembaban udara

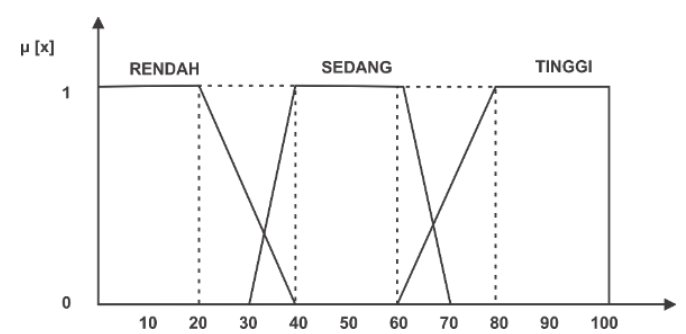

Gambar 4. Himpunan fuzzy penyinaran matahari

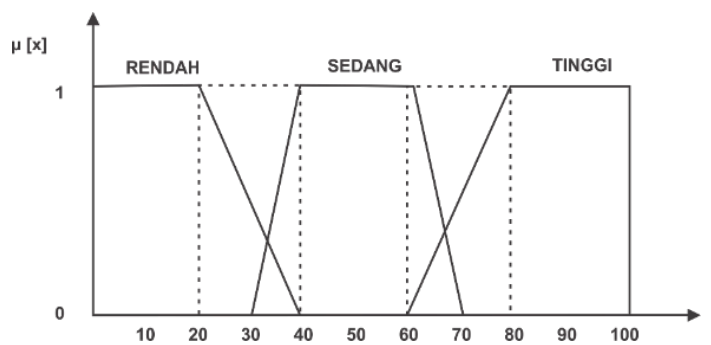

Gambar 5. Himpunan fuzzy potensi penyebaran penyakit

$$
\begin{aligned}
& \left(a_{1}-40\right) / 90=0,17 \rightarrow a_{1}=55,3 \\
& \left(a_{2}-40\right) / 90=0,40 \rightarrow a_{2}=76,00 \\
& \mu|p|= \begin{cases}0,17 & ; z \leq 55,30 \\
(z-40) / 90 & ; 55,30 \leq z \leq 76,00 \\
0,40 ; & ; z \geq 76,00\end{cases}
\end{aligned}
$$


[R1] IF pH Tanah Sedang AND Suhu Udara Sedang AND Kelembaban Udara Sedang AND Penyinaran Matahari Rendah THEN Potensi Penyakit Sedang;

apredikat $1=\mu$ phtanah $\cap \mu$ suhu $\cap \mu$ kelembaban $\cap \mu$ penyinaran matahari

$=\min (\mu$ sedang[7,5], $\mu$ sedang[28], $\mu$ sedang[75], $\mu$ rendah[35]

$=\mu \min (0,50 ; 0,40 ; 0,50 ; 0,25)$

$=0,25$

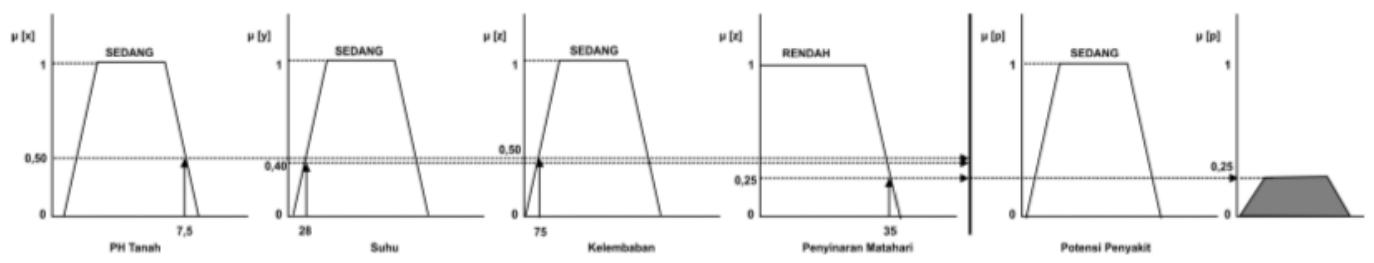

[R2] IF pH Tanah Sedang AND Suhu Udara Sedang AND Kelembaban Udara Sedang AND Penyinaran Matahari Sedang THEN Potensi Penyakit Sedang;

apredikat $2=\mu$ phtanah $\cap \mu$ suhu $\cap \mu$ kelembaban $\cap \mu$ penyinaran matahari

$=\min (\mu$ sedang $[7,5], \mu$ sedang[28], $\mu$ sedang[75], $\mu$ sedang[35]

$=\mu \min (0,50 ; 0,40 ; 0,50 ; 0,50)$

$=0,40$

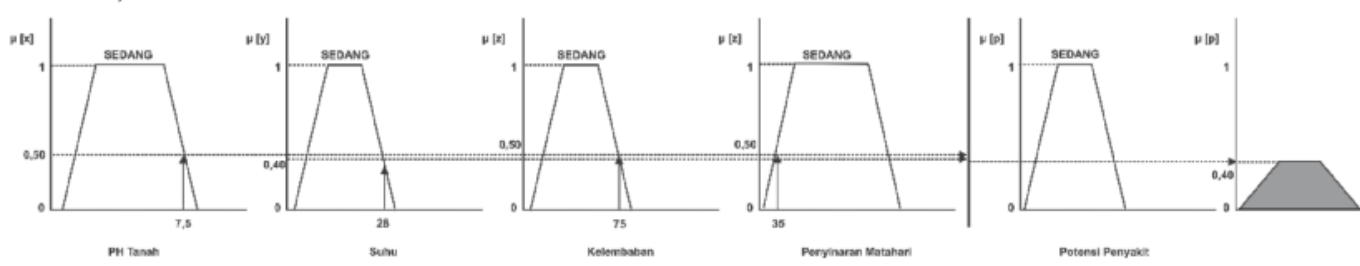

[R3] IF pH Tanah Sedang AND Suhu Udara Sedang AND Kelembaban Udara Tinggi AND Penyinaran Matahari Rendah THEN Potensi Penyakit Tinggi;

apredikat $3=\mu$ phtanah $\cap \mu$ suhu $\cap \mu$ kelembaban $\cap \mu$ penyinaran matahari

$=\min (\mu$ sedang $[7,5], \mu$ sedang[28], $\mu$ tinggi[75], $\mu$ rendah[35]

$=\mu \min (0,50 ; 0,40 ; 0,25 ; 0,25)$

$=0,25$
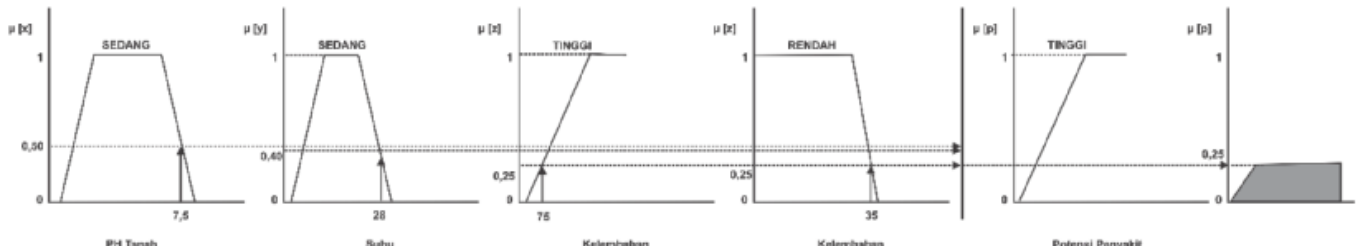

$\cdots$

[R13] IF pH Tanah Tinggi AND Suhu Udara Tinggi AND Kelembaban Udara Tinggi AND Penyinaran Matahari Sedang THEN Potensi Penyakit Tinggi;

apredikat 16= $\mu$ phtanah $\cap \mu$ suhu $\cap \mu$ kelembaban $\cap \mu$ penyinaran matahari

$=\min (\mu$ tinggi $[7,5], \mu$ tinggi[28], $\mu$ tinggi[75], $\mu$ sedang[35]

$=\mu \min (0,17 ; 0,30 ; 0,25 ; 0,50)$

$=0,17$

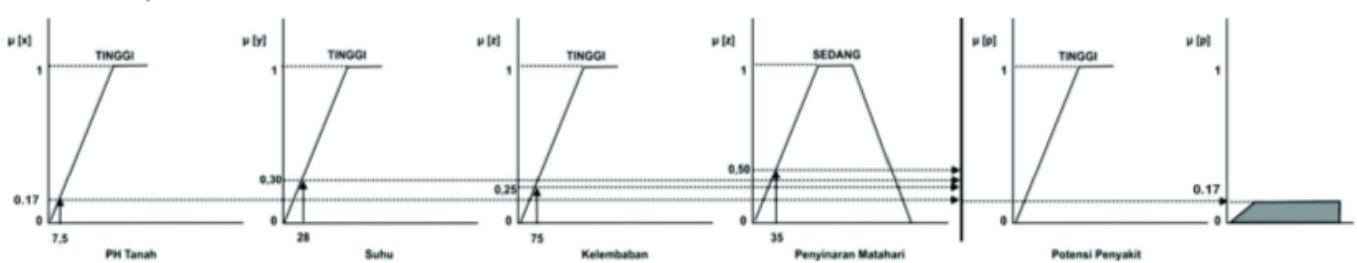

Gambar 6. Fungsi implikasi dalam studi kasus yang melibatkan 13 aturan 


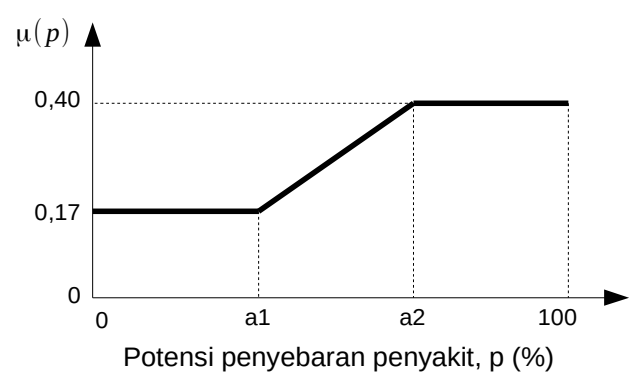

Gambar 7. Komposisi aturan dalam studi kasus

Tahap penegasan (defuzzifikasi) untuk menentukan potensi penyebaran penyakit tanaman cabai (capsicum annum l) menggunakan metode centroid. Perhitungan momen setiap daerah himpunan (M), luas setiap daerah (A) dan titik pusatnya (Z) menggunakan Persamaan 1 dan Persamaan 2 sebagai berikut:

$$
\begin{aligned}
Z & =\frac{M 1+M 2+M 3}{A 1+A 2+A 3} \\
& =\frac{\int_{0}^{55,3} 0,17 z d z+\int_{55,30}^{76} \frac{(z-40)}{90} z d z+\int_{76}^{76} 0,4 z d z}{\int_{0}^{55,3} 0,17 d z+\int_{55,30}^{100} \frac{(z-40)}{90} d z+\int_{76}^{100} 0,4 d z} \\
& =60,25
\end{aligned}
$$

Hasil nilai persentase potensi penyebaran penyakit menunjukkan angka $60,25 \%$, sehingga kategori penyebaran potensi penyakit dengan $\mathrm{PH}$ Tanah $7.5 \mathrm{pH}$, Suhu Udara $28^{\circ} \mathrm{C}$ dan Kelembaban Udara $75 \mathrm{RH}$ dan Penyinaran Matahari 35\% adalah SEDANG sesuai dengan Tabel 1. Dengan adanya sistem pakar berbasis fuzzy Mamdani ini, selain deteksi penyakit cabai dapat dideteksi dengan [5]-[8], potensi penyebarannya pun dapat dihitung kemungkinannya dengan memperhatikan empat parameter lingkungan, yaitu $\mathrm{pH}$ tanah, suhu udara, kelembaban udara dan penyinaran matahari. Tingkat ketepatan prediksi penyebaran penyakit menggunakan fuzzy Mamdani ini masih perlu untuk diuji seperti halnya dalam [11], [12]. Untuk implementasi pengukuran lama penyinaran matahari, sistem untuk mengukur intensitas cahaya secara fuzzy seperti dalam [13] dapat digunakan. Selain itu, fuzzy Sugeno dapat dikembangkan untuk prediksi potensi penyebaran penyakit cabai ini untuk mendapatkan performansi sistem dengan kapasitas penuh [9], [10].

\section{KESIMPULAN}

Sistem pakar untuk diagnosis potensi penyebaran penyakit pada tanaman cabai dapat dikembangkan dengan menggunakan fuzzy Mamdani berdasarkan parameter masukan lingkungan berupa $\mathrm{pH}$ tanah, suhu udara, kelembaban udara, penyinaran matahari dan potensi penyakit.

\section{UCAPAN TERIMA KASIH}

Ucapan terima kasih disampaikan kepada Ibu Lilik Retnowati, S. P, di Balai Besar Peramalan Organisme Pengganggu Tumbuhan Karawang yang berperan sebagai pakar dalam penelitian ini.

\section{Daftar Pustaka}

[1] M. Syukur, S. Sujiprihati, R. Yunianti, and D. A. Kusumah, "Evaluasi Daya Hasil Cabai Hibrida dan Daya Adaptasinya di Empat Lokasi dalam Dua Tahun," Jurnal Agronomi Indonesia (Indonesian Journal of Agronomy), vol. 32, no. 1, pp 43-51, 2010.

[2] Berita Resmi Statistik, "Produksi Cabai Besar, Cabai Rawit, Dan Bawang Merah Tahun 2014," Badan Pusat Statistik (BPS), Jakarta, 2015.

[3] W. O. Muliastuty, S. R. P. Sitorus, R. Poerwanto, and H. Hardjomidjojo, "Teknik Pengelolaan Usaha Tani Tanaman Cabai Berkelanjutan Di Dataran Tinggi Kecamatan Cikajang Kabupaten Garut," Jurnal Manusia dan Lingkungan, vol. 23, no. 1, pp. 66-75, 2016.

[4] A. S. Duriat, N. Gunaeni, and A. W. Wulandari, "Penyakit Penting Pada Tanaman Cabai dan Pengendaliannya," Monografi No. 31, Balai Penelitian Tanaman Sayuran, Bandung, 2007.

[5] D. O. Nusantara, S. W. Pamungkas, N. R. Syaifudin, L. W. Kusuma, and J. Fikri, "Sistem Pakar Analisa Penyakit pada Tanaman Cabai Merah Menggunakan Metode Backward Chaining," Semnasteknomedia Online, vol. 5, no. 1, pp. 73-78, 2017.

[6] M. Fuljana, "Sistem Pakar Diagnosis Penyakit Tanaman Cabai Menggunakan Metode Forward Chaining Berbasis Android," Skripsi, Universitas Lampung, 2017.

[7] A. A. Muslim, R. Arnie, and S. Sushermanto, "Sistem Pakar Diagnosa Hama dan Penyakit Cabai Berbasis Teorema Bayes," JUTISI, vol. 4, no. 3, pp. 867-876, Desember 2015.

[8] M. Mulyanto, "Sistem Pakar Fuzzy untuk Diagnosis Penyakit pada Tanaman Cabai Merah," Skripsi, Institut Pertanian Bogor, 2011.

[9] S. Kusumadewi, Artificial Intelligence (Teknik dan Aplikasinya). Graha Ilmu, Yogyakarta, 2003.

[10] A. Kaur, and A. Kaur, "Comparison of MamdaniType and Sugeno Type Fuzzy Inference Systems for Air Conditioning System," International Journal of Soft Computing and Engineering (IJSCE), vol. 2, no. 2, pp. 323-325, May 2012.

[11] M. Blej, and M. Azizi, "Comparison of MamdaniType and Sugeno-Type Fuzzy Inference Systems for Fuzzy Real Time Scheduling," International Journal of Applied Engineering Research, vol 11, no. 22, pp. 11071-11075, 2016.

[12] S. Batubara, "Analisis Perbandingan Metode Fuzzy Mamdani dan Fuzzy Sugeno untuk Penentuan Kualitas Cor Beton Instan," IT Journal Research and Development, vol. 2, no. 1, pp. 1-11, Agustus 2017.

[13] A. Mukti, O. D. Nurhayati, and E. D. Widianto, "Rancang Bangun Sistem Kontrol Robot Line Follower Menggunakan Logika Fuzzy," Jurnal Teknologi dan Sistem Komputer, vol. 3, no. 4, pp. 536-543, Oktober 2015. 